\section{Antitumor potential of Citrus limetta fruit peel in Ehrlich ascites carcinoma bearing Swiss albino mice}

\author{
Sriparna KunduSen, ${ }^{1}$ Asis Bala, 1 \\ Biswakanth Kar,1 Sanjib Bhattacharya,2 \\ Upal K. Mazumder,1 Malaya Gupta,1 \\ Pallab K. Haldar ${ }^{1}$ \\ 1Department of Pharmaceutical \\ Technology, Jadavpur University, Kolkata, \\ West Bengal; 2Bengal School of \\ Technology (a College of Pharmacy), \\ Sugandha, Hooghly, West Bengal, India
}

\section{Abstract}

Citrus limetta Risso (Rutaceae), commonly known as sweet lime in English and Mousambi in India, has been traditionally used for several medicinal purposes. This study explored the relationship between Citrus limetta fruit peel and its antitumor activity against Ehrlich ascites carcinoma (EAC) bearing mice. The antitumor activity of methanol extract of peel of Citrus limetta fruits (MECL) was evaluated against EAC cell line in Swiss albino mice. Twenty-four hours after intraperitoneal inoculation of tumor EAC cells in mice, MECL was administered at 200 and $400 \mathrm{mg} / \mathrm{kg}$ body weight i.p. daily for nine consecutive days. On the $10^{\text {th }}$ day, half of the mice were sacrificed for the estimation of tumor growth (tumor volume, viable and non-viable tumor cell counts), and hematologic parameters (red blood cells, white blood cells and hemoglobin). The rest were kept alive for assessment of survival parameters, i.e. median survival time and percentage increase in life span of EAC bearing mice. Intraperitoneal administration of MECL at the doses of 200 and $400 \mathrm{mg} / \mathrm{kg}$ for nine days to the carcinoma induced mice demonstrated a significant $(\mathrm{P}<0.001)$ decrease in tumor volume, viable tumor cell count, tumor weight and a significant $(\mathrm{P}<0.001)$ improvement in hematologica parameters and life span as compared to the EAC control mice. The present study establishes marked and dose dependant antitumor effect of $C$. limetta fruit peel against Ehrlich ascites carcinoma bearing Swiss mice.

\section{Introduction}

Cancer is considered to be one of the deadliest causes of morbidity and mortality worldwide. Unfortunately, currently available cancer chemotherapeutic agents insidiously affect the normal host cells, especially bone marrow, epithelial tissues, reticuloendothelial system and gonads. ${ }^{1}$ Plants have a long history of use in the treatment of cancer. A number of plant or other natural product extracts have been studied for anticancer activity leading to the development of several clinically useful anticancer agents. ${ }^{2}$ The natural products act by different and distinct mechanisms and/or precipitate less serious side effects. Therefore, today natural products are regarding as being exceptionally valuable in the development of effective anticancer drugs with minimum host cell toxicity. The rich wealth of the plant kingdom can represent a novel source of new compounds with desired therapeutic activity against neoplastic diseases. ${ }^{3}$

Citrus limetta Risso (Rutaceae), is commonly known as sweet lime in English and Mousambi in India. The plant is indigenous to South America. 4 The plants of the Citrus genus are renowned for their medicinal properties which are attributed to the limonoids and flavonoids present in them and which are thought to be responsible for their use in traditional antitumor and anti-inflammatory treatment.5,6 In Mexico, its fruits are used for their antihyperglycemic and antihypertensive activity. 7,8 The leaf extract was evaluated for its antagonistic activity on the hypertensive action of angiotensin II. 8 The fruit has shown anti-inflammatory and antithrombotic action.911 The fruit peel has shown potent anti-inflammatory activity at the dose of $400 \mathrm{mg} \mathrm{kg}^{-1}$ when compared with phenylbutazone. ${ }^{12}$

$C$. limetta root extract at the concentration of $500 \mu \mathrm{g} / \mathrm{mL}$ was found to be lethal towards the larvae of brine shrimp (Artemia franciscana) in a study conducted in the Amazonas state of Brazil, which serves as a pre-screen to existing cytotoxicity and antitumor assays.13 Flavonoids hespiridin and naringin are found to be present in the peel and inner part of the fruit of $C$. limetta. ${ }^{10}$ The essential oil constituents, namely -pinene, -pinene, sabinene, -myrcene, para-cymene, limonene, -terpinene, neryl acetate, -bisabolene, -bergamotene, were isolated from the zests of $C$. limetta. ${ }^{14}$ Limonene, -terpinene was isolated from the fruit peel and their minimum inhibitory concentration and maximal tolerated concentration was estimated against Pseudomonas putida. ${ }^{4}$ The present study aimed to evaluate the possible antitumor effect of $C$. limetta fruit peels against Ehrlich ascites carcinoma (EAC) in Swiss albino mice.

\section{Materials and Methods}

\section{Plant materia}

Fresh fruits of Citrus limetta were collected from the Nadia region of West Bengal, India, in
Correspondence: Pallab Kanti Haldar, Department of Pharmaceutical Technology, Jadavpur University, Kolkata 700032, West Bengal, India.

Tel. + 91.9433230566 - Fax: + 91.3324146046

E-mail: pallab_haldar@rediffmail.com

Key words: antitumor, 5-fluorouracil, hematologic, median survival time.

Acknowledgements: the authors would thank the University Grants Comission (UGC), New Delhi, India, for financial assistance and the authority of Jadavpur University, Kolkata 700032, India, for providing the necessary facilities for the present study.

Conflict of interests: the authors report no conflict of interests.

Received for publication: 16 September 2011. Accepted for publication: 20 April 2012

This work is licensed under a Creative Commons Attribution NonCommercial 3.0 License (CC BYNC 3.0).

(C) Copyright S. KunduSen et al., 2012

Licensee PAGEPress, Italy

Alternative Medicine Studies 2012; 2:e10

doi:10.4081/ams.2012.e10

the months of March-April 2007. The plant material was authenticated by Dr M.S. Mondal from the Central National Herbarium, Botanical Survey of India, Shibpur, Howrah, West Bengal, India, and the voucher specimen (PMU-2/JU/2007) was preserved in our research laboratory for further reference.

\section{Preparation of extract}

Fresh mature fruit peels of $C$. limetta were removed from the fruits manually, taking care not to include the membranous matter and pith. The peels were shade-dried at room temperature $\left(24-26^{\circ} \mathrm{C}\right)$ and ground mechanically into a coarse powder. The powdered plant material $(500 \mathrm{~g})$ was macerated at room temperature $\left(24-26^{\circ} \mathrm{C}\right)$ for seven days in petroleum ether and successively methanol. The methanol extract was evaporated under reduced pressure to obtain the dry extract [methanol extract of peel of Citrus limetta fruits (MECL) yield: $10.56 \% \mathrm{w} / \mathrm{w}]$. The MECL was then stored in a vacuum desiccator until used. Preliminary phytochemical studies were performed on MECL as per reported methods..$^{15}$

\section{Drugs and chemicals}

Sodium chloride, trypan blue, methyl violet, methylene blue, 5-fluorouracil were from Merck Ltd., Mumbai, India. All the other reagents used were of analytical grade and were obtained commercially. 


\section{Experimental animals}

Male Swiss albino mice weighing 20-22 g obtained from Reeta Ghosh and Co., Kolkata, India, were used for the present study. They were acclimatized to the laboratory conditions for seven days prior to the study. The animals were kept at $25 \pm 2^{\circ} \mathrm{C}$ and a relative humidity of $40-45 \%$ with alternative day and night cycles of $12 \mathrm{~h}$ each. The animals had free access to pellet food (Hindustan Lever, Mumbai, India) and water ad libitum. All experimental procedures described were reviewed and approved by the University Animal Ethical Committee, Jadavpur University (367001/C/CPCSEA).

\section{Acute toxicity}

The acute toxicity of the extract was determined according to the OECD guideline n. 420 in male Swiss mice. ${ }^{16}$ MECL was given orally to four groups ( $n=6$ ) of animals once at 5, 50, 300 and $2000 \mathrm{mg} / \mathrm{kg}$ body weight (bw). The treated animals were kept under observation for 14 days for mortality and general behavior. No death was observed till the end of the study. The test extract MECL was found to be safe up to the dose of $2000 \mathrm{mg} / \mathrm{kg}$.

\section{Preparation of tumor cells}

The EAC cells were obtained from Chittaranjan National Cancer Institute - CNCI, Kolkata, West Bengal, India. The EAC cells were maintained in the ascitic form in vivo in Swiss albino mice by means of serial intraperitoneal transplantation of $2 \times 10^{6}$ cells/mouse after every ten days. Ascitic fluid was drawn out from EAC bearing mouse eight days after transplantation. The freshly drawn fluid was diluted with ice-cold sterile normal saline and the tumor cell count was adjusted to $2 \times 10^{7}$ cells $/ \mathrm{mL}$ by sterile normal saline. ${ }^{17}$

\section{Treatment protocol}

The animals were divided into five groups $(n=12)$. Except for the first group, all groups received $0.1 \mathrm{~mL}$ of EAC cell suspension $\left(2 \times 10^{6}\right.$ cells/mouse, i.p.). This was taken to be day 0 . The first group served as normal saline control (received isotonic saline $5 \mathrm{~mL} / \mathrm{kg}$ body weight i.p.). The second group served as EAC control. After $24 \mathrm{~h}$ of tumor inoculation the $3^{\text {rd }}$ and $4^{\text {th }}$ group received MECL at the doses of 200 and $400 \mathrm{mg} / \mathrm{kg}$ body weight, p.o. respectively, and the $5^{\text {th }}$ group received the reference drug 5 -fluorouracil ( $20 \mathrm{mg} / \mathrm{kg}$ body weight, p.o.) for nine consecutive days. Twenty-four hours after the last dose and after $18 \mathrm{~h}$ of fasting, blood was collected from 6 mice of each group by cardiac puncture for the estimation of hematologic parameters. These mice were then sacrificed by cervical dislocation for the study of antitumor parameters. The other 6 mice of each group were kept alive with food and water ad libitum to assess the increase in the life span of the tumor bearing hosts. The antitumor effect of MECL was assessed by determination of tumor volume, viable and non-viable cell counts, median survival time (MST) and percentage increase in life span (\% ILS). ${ }^{18}$

\section{Tumor volume}

The ascitic fluid was collected from the peritoneal cavity. The volume was measured in a graduated centrifuge tube.

\section{Tumor cell count}

The ascitic fluid was taken in a white blood cell pipette and diluted 100 times. Then a drop of the diluted cell suspension was placed on the Neubauer's counting chamber and the numbers of cells in the 64 small squares were counted.

\section{Viable and non-viable tumor cell counts}

The viability and non-viability of the cell were checked by trypan blue dye exclusion assay. The cells were stained with trypan blue ( $0.4 \%$ in normal saline) dye. The cells that did not take up the dye were viable and those that took the dye were non-viable. These viable and non-viable cells were counted.

Cell count $=(n$. of cells $\times$ dilution factor $) /($ area $\times$ thickness of liquid film)

\section{Median survival time and percent- age increase in life span}

The animals were observed for their mortality daily until their death or up to a maximum of 45 days. Mortality was monitored by recording MST and percentage increase in life span (\% ILS) as per the following formulae:

MST $^{*}=($ first death + last death $) / 2$

where ${ }^{*}$ is time denoted by number of days. $\%$ ILS $=[($ MST of MECL treated group/ MST of EAC control group) - 1)] $\times 100$

\section{Hematologic parameters}

Collected blood was used for the estimation of hemoglobin content; red blood cell count and white blood cell count. ${ }^{19,20}$

\section{Statistical analysis}

Most data are expressed as mean \pm standard error of mean (SEM). Statistical significance was calculated by one-way analysis of value between the treated groups and the EAC control followed by Dunnett's post hoc test of significance where $\mathrm{P}<0.001$ were considered to be statistically significant. For this, the Graph Pad Prism software version 5.0 was used.

\section{Results}

Preliminary qualitative phytochemical analysis revealed the presence of flavonoids, alkaloids, tannins and saponins in MECL. In the present study, intraperitoneal administration of MECL at the dose levels of 200 and 400 mg kg-1 body weight increased the life span, non-viable tumor cell count, and decreased the tumor volume and viable tumor cell count compared to the EAC control mice (Table 1). MST being an average of the first death and the last

Table 1. Effect of methanol extract of peel of Citrus limetta fruits on median survival time, percentage increase in life span, tumor volume, total, viable, and non-viable cell counts of Ehrlich ascites carcinoma bearing mice.

\begin{tabular}{lcccc} 
Parameters & EAC control & MECL 200 mg/kg & MIECL 400 mg/kg & 5 -FU 20 mg/kg \\
Tumor volume (mL) & $3.81 \pm 0.28$ & $1.96 \pm 0.50^{*}$ & $0.72 \pm 0.15^{*}$ & $0.74 \pm 0.18^{*}$ \\
MST (days) & 17.5 & 27.5 & 30.5 & 34.5 \\
\hline$\%$ ILS & - & 57.14 & 74.29 & 97.14 \\
Viable cell $\times 10^{7}$ & $11.2 \pm 0.21$ & $3.8 \pm 0.03^{*}$ & $1.9 \pm 0.07^{*}$ & $1.03 \pm 0.04^{*}$ \\
Nonviable cell $\times 10^{7}$ & $0.5 \pm 0.01$ & $1.4 \pm 0.30^{*}$ & $2.5 \pm 0.03^{*}$ & $3.2 \pm 0.05^{*}$ \\
\hline Total cell $\times 10^{7}$ & 11.7 & 5.2 & 4.4 & 4.23 \\
Viable $\%$ & 95.7 & 73.1 & 53.2 & 24.3 \\
\hline Nonviable $\%$ & 4.3 & 26.9 & 56.8 & 75.7 \\
\hline
\end{tabular}

EAC, Ehrlich ascites carcinoma; MECL, methanol extract of peel of Citrus limetta fruits; MTS, median survival time; ILS, increase in life span. Values are mean \pm standard error of mean (n=6). Treated groups compared with EAC control group $\left({ }^{*} \mathrm{P}<0.001\right)$. 
death time in a group, there was no SEM value for calculation. Percentage increase in life span was calculated for each group by comparing the MST with that of the control group. Therefore, no SEM value was reported. Similarly total cell count was the additive total of viable and non-viable cell counts in a group. Therefore, no SEM values were reported. The percentage viable and non-viable cells were calculated by comparing the viable and nonviable cell count with respect to the total cell count. MECL also restored the altered hematologic parameters of the EAC bearing mice near to normal levels when compared to those of EAC control mice (Table 2).

\section{Discussion}

We aimed to study the antitumor activity of defatted methanol extract of $C$. limetta fruit peel in EAC bearing mice. Our results showed that MECL at both test doses was able to significantly decrease the white blood cell count from blood and prolonged life span as compared to that of the EAC control group. One of the major criteria for judging clinically effective antineoplastic agents is that it should be able to prolong the survival and decrease the leukocyte count of blood of tumor bearing animals. ${ }^{21,22}$ It has been reported that a $25 \%$ or over increase in life span of EAC bearing animals is considered to be indicative of significant antitumor activity. ${ }^{23}$ It can, therefore, be inferred that MECL significantly enhanced the life span of EAC bearing mice indicating its antitumor potential.

Cancer is a pathological state involving uncontrolled proliferation of tumor cells. Reduced volume of tumor and viable cells indicated a decrease in abnormal cell divisions, i.e. tumor proliferation. ${ }^{17,24}$ In cancer chemotherapy, the major problems are usually myelosuppression and anemia. 25 Results of the present study indicated that MECL dose dependently and significantly raised the erythrocyte count and hemoglobin content when compared to those of EAC control mice. The white blood cell count was significantly reduced as compared with that of EAC control mice. These indicated that MECL had less or no toxic effects on the blood and hematopoietic system, thereby maintaining a normal hematologic profile in EAC bearing mice. ${ }^{3}$

Preliminary phytochemical studies indicated the presence of flavonoids, alkaloids, tannins and saponin in MECL. Flavonoids and tannins are well known polyphenolic natural antioxidants. The flavonoids present in citrus plants are thought to be the cause of their antitumor and anti-inflammatory effects. ${ }^{5}$ Flavonoids have a chemopreventive role in cancer by means of their effect in signal transduction in cell proliferation and angiogenesis. ${ }^{26} \mathrm{An}$ in vitro antioxidant activity of MECL against different reactive oxygen and nitrogen species has already been established by the present authors. ${ }^{27}$ This important property may be responsible for its antitumor activity against EAC in vivo.

As discussed above, the peel of $C$. limetta contains flavonoids, namely hesperidin and naringin. Hesperetin, which is the aglycone of hesperidin, has shown potent inhibitory action against dimethyl benza(a)anthracene induced mammary carcinoma in Sprague-Dawley rats and liver carcinoma in ICA mice. ${ }^{28}$ Hesperetin also induced $\mathrm{G}_{1}$ phase cell cycle arrest in human breast cancer MCF-7 cells. ${ }^{29}$ Hexane and ethanol extracts of sweet lime peel and seeds have also shown an inhibitory effect on Epstein-Barr virus activation. ${ }^{30}$ Naringenin, which is the aglycone of naringin, has been proven to enhance the antitumor effect of doxorubicin by inhibition of multidrug resistance associated proteins. ${ }^{31}$ Naringenin inhibits catenin/Tcf signaling in gastric cancer although the mechanisms remain unknown. ${ }^{32}$ The citrus flavonoids hesperetin differentially regulate low density lipoprotein receptor gene transcription in HepG2 liver cells. ${ }^{33}$

Therefore, from the present study it can be concluded that fruit peel of Citrus limetta showed promising antitumor potential in Ehrlich ascites carcinoma bearing Swiss albino mice which can be attributed to its

Table 2. Effect of methanol extract of peel of Citrus limetta on hematological parameters in Ehrlich ascites carcinoma bearing mice.

\begin{tabular}{lccl} 
Treatment & $\begin{array}{c}\text { Hemoglobin }(\mathrm{g} / \mathrm{dL}) \\
(\text { cells } \times 106 / \mu \mathrm{L})\end{array}$ & $\begin{array}{c}\text { RBC count } \\
(\text { cells } \times 106 / \mu \mathrm{L})\end{array}$ & WBC count \\
Normal control group & $11.5 \pm 1.0$ & $6.3 \pm 0.4$ & $3.2 \pm 0.2$ \\
EAC control & $4.6 \pm 0.9$ & $2.9 \pm 0.3$ & $6.1 \pm 0.4$ \\
\hline EAC+MECL $(200 \mathrm{mg} / \mathrm{kg})$ & $8.1 \pm 1.1^{*}$ & $3.3 \pm 0.8^{*}$ & $4.8 \pm 0.2^{*}$ \\
EAC+MECL $(400 \mathrm{mg} / \mathrm{kg})$ & $10.1 \pm 0.7^{*}$ & $5.5 \pm 0.5^{*}$ & $4.3 \pm 0.3^{*}$ \\
\hline EAC+5FU $(20 \mathrm{mg} / \mathrm{kg})$ & $10.5 \pm 0.6^{*}$ & $5.7 \pm 0.8^{*}$ & $3.8 \pm 0.2^{*}$ \\
\hline
\end{tabular}

EAC, Ehrlich ascites carcinoma; MECL, methanol extract of peel of Citrus limetta fruits; RBC, red blood cell; WBC, white blood cell. Values are mean \pm standard error of mean $(n=6)$. Treated groups compared with $E A C$ control group $(* P<0.001)$.

flavonoid content. This could serve as a stepping stone towards the discovery of newer safe and effective antitumor agents.

\section{References}

1. Nitha B, Meera CR, Janardhanan KK. Antitumor activity of ethanolic extract of Lentinus dicholamellatus. Amala Res Bull 2005;25:165-8.

2. da-Rocha AB, Lopes RM, Schwartsmann G. Natural products in anticancer therapy. Curr Opin Pharmacol 2001;1:364-9.

3. Bhattacharya S, Prasanna A, Majumdar P, et al. Antitumor efficacy and amelioration of oxidative stress by Trichosanthes dioica root against Ehrlich ascites carcinoma in mice. Pharm Biol 2011;49:927-35.

4. Oussalah M, Caillet S, Saucier L, Lacroix M. Antimicrobial effects of selected plant essential oils on the growth of a Pseudomonas putida strain isolated from meat. Meat Sci 2006;73:236-44.

5. Middleton E, Kandaswami C, Theoharides TC. The effects of plant flavonoids on mammalian cells: implications for inflammation, heart disease, and cancer. Pharmacol Rev 2000;52:673-751.

6. Poulose SM, Harris ED, Patil BS. Citrus limonoids induce apoptosis in human neuroblastoma cells and have radical scavenging activity. J Nutrition 2005;135:870-7.

7. Andrade-Cetto A, Heinrich M. Mexican plants with hypoglycaemic effect used in the treatment of diabetes. J Ethnopharmacol 2005;99:325-48.

8. Perez YY, Jimenez-Ferrer E, Alonso D, et al. Citrus limetta leaves extract antagonizes the hypertensive effect of angiotensin II. J Ethnopharmacol 2010; 128:611-4.

9. Nogata, Y, Yoza K, Kusumoto K, et al. Screening for inhibitory activity of Citrus fruit extracts against platelet cyclooxygenase and lipoxygenase. J Agr Food Chem 1996;44:725-9.

10. Nogata Y, Sakamoto K, Shiratsuchi H, et al. Flavonoid composition of fruit tissues of citrus species. Biosci Biotechnol Biochem 2006;70:178-92.

11. Moron RF, Guerrero JR, Victoria AC. Plantas medicinales caribe as con potencialidad para inhibir la agregación de las plaquetas. Rev Cubana Plantas Med 2007;12: 1-6.

12. KunduSen S, Gupta M, Mazumder UK, et al. Exploration of anti-inflammatory potential of Citrus limetta Risso and Citrus maxima (J. Burm.) Merr. Pharmacologyonline 2011;7:702-9.

13. Quignard ELJ. Screening of plants found 
in Amazonas state for lethality towards brine shrimp. Acta Amazonica 2003;33:93104.

14. Herent MF, De Bie V, Tilquin B. Determination of new retention indices for quick identification of essential oils compounds. J Pharm Biomed Anal 2007; 43:886-92.

15. Harborne JB. Phytochemical methods, a guide to modern techniques of plant analysis. New Delhi, India: Springer Pvt. Ltd.; 1998.

16. Anonymous. OECD Guidelines for the testing of chemicals/section 4: health effects test no. 425: acute oral toxicity: up-anddown procedure. Paris: OECD Publishing; 2008.

17. Bala A, Kar B, Haldar PK, et al. Evaluation of anticancer activity of Cleome gynandra on Ehrlich's ascites carcinoma treated mice. J Ethnopharmacol 2010;129:131-4.

18. Haldar PK, Kar B, Bala A, et al. Antitumor activity of Sansevieria roxburghiana rhizome against Ehrlich ascites carcinoma in mice. Pharm Biol 2010;48:1337-43.

19. D'Armour, FE, Blood FR, Belden DA. The manual for laboratory works in mammalian physiology. Chicago, Illinois: The University of Chicago Press; 1965.

20. Wintrobe MM, Lee GR, Boggs DR, et al.
Clinical hematology. Philadelphia: Les \& Febiger; 1961.

21. Oberling $\mathrm{C}$, Guerin $\mathrm{M}$. The role of viruses in the production of cancer. Adv Cancer Res 1954;2:353-423.

22. Clarkson D, Burchneal JH. Preliminary screening of antineoplastic drugs. Prog Clin Cancer 1965;1:625-9.

23. Andreani AG, Galatulas SI. Potential antitumor agents. IX: Synthesis and antitumor activity of two analogues of ketocaine. J Pharm Sci 1983;72:814-9.

24. Gupta M, Mazumder UK, Haldar PK, Chicago. Anticancer activity of Indigofera aspalathoides and Wedelia calendulaceae in Swiss albino mice. Iranian J Pharm Res 2007;6:141-5.

25. Hogland HC. Hematological complications of cancer chemotherapy. Semin Oncol 1982;9:95-102.

26. Wagner H, Geyer B, Yoshinobu K, Govind SR. Coumestan as the main active principles of liver drugs Eclipta alba and Wedelica calendulaceae. Planta Med 1986;5:370-2.

27. KunduSen S, Saha P, Bhattacharya S, et al. Evaluation of in vitro antioxidant activity of Citrus limetta and Citrus maxima on reactive oxygen and nitrogen species. Pharmacologyonline 2010;6:850-7.
28. Choi EJ, Kim GH. Anti-/pro-apoptotic effects of hesperetin against 7,12- dimetylbenz(a)anthracene-induced alteration in animals. Oncol Rep 2011;25:545-50.

29. Choi EJ. Hesperetin induced G1-phase cell cycle arrest in human breast cancer MCF7 cells: involvement of CDK4 and p21. Nutr Cancer 2007;59:115-9.

30. Iwase Y. Inhibitory effect of Epstein-Barr virus activation by Citrus fruits, a cancer chemopreventor. Cancer Lett 1999;139: 227-36.

31. Zhang F, Du GJ, Zhang L, et al. Naringenin enhances the anti-tumor effect of doxorubicin through selectively inhibiting the activity of multidrug resistance-associated proteins but not P-glycoprotein. Pharm Res 2009;26:914-25.

32. Lee JH, Park CH, Jang $\mathrm{KC}$, et al. Negative regulation of $\beta$-catenin/Tcf signaling by Naringenin in AGS gastric cancer cell. Biochem Biophys Res Comm 2005;335: 771-6.

33. Morin B, Nichols LA, Zalasky KM, et al. The citrus flavonoids hesperetin and nobiletin differentially regulate low density lipoprotein receptor gene transcription in HepG2 liver cells. J Nutr 2008;138:1274-81. 